\title{
Oesophageal manometry in the evaluation of megacolon with onset in adult life
}

\author{
G Basilisco, P Velio, P A Bianchi
}

\begin{abstract}
Background-Oesophageal motility is often impaired in patients with megaduodenum and other forms of intestinal pseudo-obstruction in which a visceral myopathy or neuropathy may be present. Idiopathic longstanding megacolon with onset in adult life is still a poorly defined entity, which may also be part of a more widespread motility disorder but in which oesophageal motility has not been yet systematically studied.
\end{abstract}

Aim-To assess oesophageal motility in patients with longstanding idiopathic megacolon with onset in adult life.

Patients-14 consecutive subjects with idiopathic megacolon whose symptoms began after the age of 10 and a clinical history of 2-22 years.

Methods-Standard barium enema, water perfused oesophageal manometry, and also anorectal manometry.

Results-Oesophageal motility was impaired in five patients $(36 \% ; 95 \%$ confidence intervals 16 to $61 \%$ ). Normal peristalsis was substituted by low amplitude multiple peaked simultaneous contractions in four subjects and by undetectable contractions in one. In three of them the lower oesophageal sphincter did not relax after swallows; in the same patients anal relaxation after rectal distension was also undetectable. All five patients with impaired oesophageal motility had a colonic dilatation sparing the rectum. Three of them reported constipation and a history of pesudoobstruction and the other two only abdominal distension.

Conclusions-Oesophageal manometry should be performed in patients with longstanding idiopathic megacolon with onset in adult life, in particular if the rectum is not dilated and even in absence of pseudoobstruction. This simple test may disclose a more widespread visceral neuropathy or myopathy. Such a diagnosis helps to better understand the cause of the colonic dilatation and may be clinically relevant for treatment of the patients.

(Gut 1997; 40: 188-191)

Keywords: megacolon, oesophageal motility, pseudo-obstruction.

Oesophageal motility is impaired in patients with visceral myopathy and megaduodenum. ${ }^{1-3}$ Most of these patients present with intestinal pseudo-obstruction, ${ }^{1-3}$ but some of them may be asymptomatic despite the enlarged duodenum. ${ }^{13-5}$ Idiopathic megacolon in adult age may manifest acutely or there may be a long history of bowel disturbances. Some patients with the latter have few symptoms, others complain of constipation, and a few with pseudo-obstruction. ${ }^{6}$ The condition is still poorly defined but in some cases at least colonic dilatation is caused by an underlying visceral myopathy or neuropathy. ${ }^{36}$ In this study we explored the possibility that a systematic assessment of oesophageal motility might be helpful to detect cases in which megacolon is a part of a more widespread motor disorder. We assessed oesophageal motility in a series of 14 consecutive patients with longstanding idiopathic megacolon with onset in adult life. Anorectal manometry was also performed in all patients. Results were compared with those obtained in healthy subjects.

\section{Methods}

\section{Patients}

Fourteen consecutive patients $(10$ men, mean age 38 years, range 16-69) with longstanding idiopathic megacolon were studied. The diagnosis of megacolon was made from radiographs obtained during barium enema examination using a standard double contrast technique. Colonic width was over $9 \mathrm{~cm}$ in at least one segment. Three patients had megarectum that is, rectal width of over $6.5 \mathrm{~cm}$ measured from lateral pelvic radiographs at the pelvic brim. ${ }^{7}$ Symptoms, when present, began after the age of 10 years. The mean interval of time from radiological diagnosis or symptoms onset was nine years, range 2-22. All but two patients complained of abdominal distension. Eight patients reported two or less bowel movements per week; four of them had a history of intestinal pseudo-obstruction. None of them experienced soiling. Two patients had a partial colectomy for megacolon. Three reported oesophageal symptoms; reflux symptoms in two and chest pain in one.

None of the patients had travelled in countries where Chagas' disease is endemic or in east Africa. Neoplastic and collagen diseases and diseases of the central nervous system such as myotonic dystrophy, parkinsonism, and multiple sclerosis were excluded as were spinal cord lesions, diabetic visceral neuropathy, hypothyroidism, hypoparathyroidism, and amyloidosis. None of the patients had megaduodenum or small bowel dilatation or took drugs delaying gastrointestinal motility. Routine laboratory investigations were unremarkable and, in particular, serum concen- 
trations of potassium and calcium were normal. Two patients were mentally retarded; one of them, a 28 year old woman, refused oesophageal manometry.

\section{Study design}

Oesophageal and anorectal manometry were performed after an overnight fast with multilumen catheters perfused with distilled water using a low compliance perfusion system (Arndorfer Specialties, Greendale, Wisconsin, USA) at a rate of $0.5 \mathrm{ml} / \mathrm{min}$. Pressures were transmitted to external pressure transducers and recorded on a computer.

Oesophageal manometry was performed according to Richter et al. ${ }^{8}$ An eight lumen polyvinyl tube (outer diameter $4.5 \mathrm{~mm}$; inner diameter of each lumen $0.8 \mathrm{~mm}$; Arndorfer Specialties, Greendale, Wisconsin, USA) was introduced through the nose into the oesophagus. With the distal four openings spaced $1 \mathrm{~cm}$ apart at $90^{\circ}$ and radially oriented, lower oesophageal sphincter (LOS) pressure was recorded by the station pull through technique $(0.5 \mathrm{~cm}$ increments $/ 30$ seconds $)$. The tube was then positioned to record oesophageal motility $3,8,13,18$, and $23 \mathrm{~cm}$ above the upper border of the LOS. Water perfusion of the first two orad openings of the tube was stopped to avoid pharyngeal stimulation by water. For the assessment of oesophageal peristalsis the subjects were asked to swallow $5 \mathrm{ml}$ of water 10 times at 30 second intervals. The mean station pull through pressure of the LOS was calculated as the average of the values obtained from the four radial openings, measured from the gastric baseline to the mid-point of respiratory variations. The amplitude and duration of oesophageal contractions were calculated as the average of the values obtained during the 10 wet swallows; the amplitude was measured from the intraoesophageal baseline to the peak of the pressure wave and the duration from the point where the upstroke of the contraction left the baseline to the point where the downstroke of the contraction returned to baseline. The individual values for the recording sites $3 \mathrm{~cm}$ and $8 \mathrm{~cm}$ above the LOS were averaged and considered as amplitude and duration of distal oesophageal contractions. ${ }^{8}$ Oesophageal manometry was also performed in 15 healthy subjects (nine women, mean age 33 years, range 23-59).

Anorectal manometry was performed using a polyvinyl tube (outer diamter $4.8 \mathrm{~mm}$; inner diameter of each lumen $0.8 \mathrm{~mm}$; Arndorfer Specialities, Greendale, Wisconsin, USA) with four open tipped recording catheters plus a central lumen (inner diameter $1.8 \mathrm{~mm}$ ) for inflation of a rubber rectal balloon with air. At $60 \mathrm{ml}$ of distension the mean (SD) pressure inside the balloon was 91 (2) $\mathrm{mm} \mathrm{Hg}$ and the diameter was 41 (6) $\mathrm{mm}$. Side openings were spaced $1 \mathrm{~cm}$ apart and were oriented at angles of $90^{\circ}$. The probe was inserted with the patients lying in the right lateral position, with hips flexed at $90^{\circ}$. The side openings were placed in the anal sphincter $0.5,1 \cdot 5,2 \cdot 5$, and $3.5 \mathrm{~cm}$ from the anal verge. The caudal edge of the distending rectal balloon was $7 \mathrm{~cm}$ from the anal verge. Anorectal motility was recorded for 15 minutes in resting conditions. After the resting period, subjects were asked to contract the anal sphincter maximally. This was repeated twice with a gap of one minute between contractions. The rectal balloon was then serially inflated with air to $10,20,30,40,50$, 60 , and $70 \mathrm{ml}$ using a hand held syringe. Inflations were performed rapidly (less than two seconds), maintained for one minute, and separated by one minute intervals. Immediately after the introduction of each new volume, the subject was asked whether he or she felt the distension or the desire to defecate. The following measurements were recorded: (a) the resting pressure of the anal canal, as the mean pressure recorded in the recording channel with the highest pressure at the end of the resting period; (b) the squeeze pressure, as the mean maximal pressure in the recording channel with the highest pressure during squeeze; (c) the threshold volume of the rectal balloon eliciting the feeling of distension or the desire to defecate; if the feeling of distension or the desire to defecate was not reached at the maximal distending volume of $70 \mathrm{ml}$, this volume was used for calculation purposes; (d) the volume eliciting the rectoanal inhibitory reflex, as the presence of a detectable reduction in pressure of the anal canal after rectal distension in at least one recording channel. Anorectal manometry was also performed in 11 healthy subjects (nine men, mean age 38 years, range 19-58).

All patients with impaired oesophageal motility underwent barium oesophagography and in the presence of oesophageal symptoms, also endoscopy of the upper gastrointestinal tract. Results are given as mean (SD). Continuous variables were compared by analysis of variance followed by Tukey's test for multiple comparisons. Fisher's exact test was used to compare frequency data. Ninety five per cent confidence intervals of percentages were also calculated. ${ }^{9}$

\section{Results}

Oesophageal motility was normal in nine patients whereas in four normal controls oesophageal peristalsis was substituted by simultaneous low amplitude multiple peaked contractions and in one by the absence of detectable contractions (Figure). Thus oesophageal peristalsis was impaired in five patients ( $36 \% ; 95 \%$ confidence intervals 16 to $61 \%$ ) and in none of the controls $(p<0 \cdot 05)$. None of this subgroup of patients had radiographic dilatation of the oesophagus. Three of them reported oesophageal symptoms, heartburn, and regurgitation in two cases and chest pain in the other; none of the three had gross oesophagitis at endoscopy. Table I shows the results of oesophageal manometry in controls and in patients subdivided according to impairment of oesophageal motility. The amplitude of waves in the distal oesophagus was significantly reduced and their duration was significantly prolonged in patients with impaired 


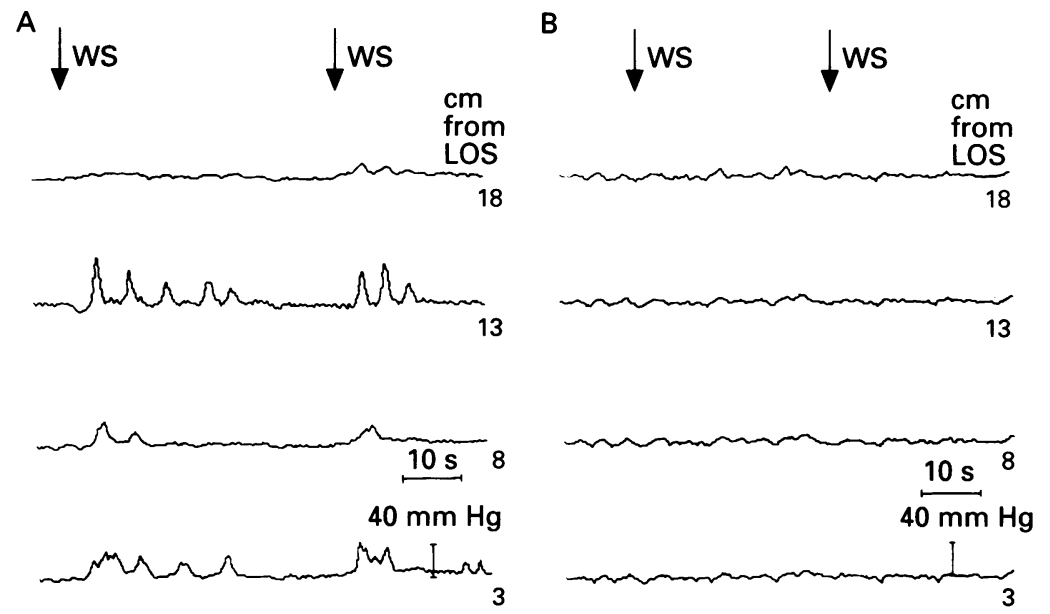

Oesophageal manometry in two patients with megacolon, one $(A)$ with simultaneous low amplitude multiple peaked contractions after wet swallows (WS) and one (B) without any contraction (LOS=lower oesophageal sphincter).

TABLE I Oesophageal motility in controls and patients with megacolon subdivided according to the presence or absence of peristaltic contractions in the oesophagus (data are mean (SD))

\begin{tabular}{|c|c|c|c|}
\hline \multirow[b]{2}{*}{$\begin{array}{l}\text { Oesophageal peristalsis } \\
\text { Subjects }(n)\end{array}$} & \multirow{2}{*}{$\begin{array}{l}\text { Controls } \\
\text { Present } \\
15\end{array}$} & \multicolumn{2}{|l|}{ Patients } \\
\hline & & $\begin{array}{l}\text { Present } \\
8\end{array}$ & $\begin{array}{l}\text { Absent } \\
5\end{array}$ \\
\hline $\begin{array}{l}\text { LOS resting pressure }(\mathrm{mm} \mathrm{Hg}) \\
\text { Absent LOS relaxation }(\mathrm{no}) \\
\text { Distal amplitude }(\mathrm{mm} \mathrm{Hg}) \\
\text { Distal duration (s) }\end{array}$ & $\begin{array}{l}17(15) \\
0 \\
83(30) \\
3 \cdot 3(0 \cdot 2)\end{array}$ & $\begin{array}{l}27(11) \\
0 \\
86(38) \\
3 \cdot 9(0 \cdot 3)\end{array}$ & $\begin{array}{l}23(11) \\
3^{\star} \\
27(22)^{\star \star} \\
5 \cdot 4 \dagger(0 \cdot 3)^{\star \star}\end{array}$ \\
\hline
\end{tabular}

${ }^{\star} \mathrm{p}<0.05 v$ controls; ${ }^{\star \star} \mathrm{p}<0.01 v$ controls and patients with normal oesophageal motility; tmeasured in four patients.

TABLE II Anorectal motility in control subjects and patients with megacolon subdivided according to the presence or absence of peristaltic contractions in the oesophagus (data are mean (SD))

\begin{tabular}{|c|c|c|c|}
\hline \multirow[b]{2}{*}{$\begin{array}{l}\text { Oesophageal peristalsis } \\
\text { Subjects }(n)\end{array}$} & \multirow{2}{*}{$\frac{\text { Controls }}{\text { Present }}$} & \multicolumn{2}{|l|}{ Patients } \\
\hline & & $\begin{array}{l}\text { Present } \\
8\end{array}$ & $\begin{array}{l}\text { Absent } \\
5\end{array}$ \\
\hline \multicolumn{4}{|l|}{ Anal pressures (mm Hg) } \\
\hline $\begin{array}{l}\text { resting } \\
\text { squeeze }\end{array}$ & $\begin{array}{r}79(21) \\
200(21)\end{array}$ & $\begin{array}{r}78(11) \\
185(60)\end{array}$ & $\begin{array}{r}62(17) \\
146(32)\end{array}$ \\
\hline \multicolumn{4}{|l|}{ Rectal sensation threshold (ml) } \\
\hline $\begin{array}{l}\text { distension } \\
\text { desire to defecate }\end{array}$ & $\begin{array}{l}12(6) \\
44(17)\end{array}$ & $\begin{array}{l}34(30) \\
60(14)\end{array}$ & $\begin{array}{l}22(18) \\
54(23)\end{array}$ \\
\hline $\begin{array}{l}\text { Rectoanal inhibitory reflex } \\
\text { absent (no of subjects) } \\
\text { threshold volume (ml) }\end{array}$ & $\begin{array}{l}0 \\
15(12)\end{array}$ & $\begin{array}{l}0 \\
41(26)^{\star}\end{array}$ & $35^{3^{\star}}(21)$ \\
\hline
\end{tabular}

${ }^{\star} \mathrm{p}<0.05 v$ controls.

peristalsis in comparison with controls and patients with normal oesophageal motility. LOS relaxation after swallows was absent in three patients with impaired oesophageal peristalsis $(\mathrm{p}<0.05 v$ controls), one of whom had reflux symptoms and one chest pain.

All five patients with impaired oesophageal motility had a colonic dilatation sparing the rectum and a variable part of the sigmoid. Three of them reported constipation and a history of pseudo-obstruction; the other two complained of abdominal distension but their bowel frequency was normal. Table II shows the results of anorectal manometry. Resting and squeeze pressures of the anal sphincter and rectal sensitivity to distension in patients with impaired oesophageal motility were not different from those of controls. The reflex relaxation of the internal anal sphincter was impaired in the three patients in whom LOS relaxation was also impaired.
Of the nine patients with normal oesophageal motility, five were constipated and one had a history of pesudo-obstruction. The threshold volumes for the perception of distension, desire to defecate, and rectoanal inhibitory reflex were greater than in healthy subjects, in particular in the three patients with megarectum.

\section{Discussion}

Our study showed that five of 14 consecutive patients with idiopathic longstanding megacolon with onset in adult life had disease involving the oesophagus. In four of them, low amplitude multiple peaked simultaneous contractions were recorded in the distal oesophagus and contractions were undetectable in the fifth. The severe oesophageal motor impairment cannot be considered a variation of normal. In fact, simultaneous low amplitude multiple peaked contractions were never observed in our healthy subjects after 10 wet swallows and only in four subjects after one wet swallow of a series of 95 healthy subjects studied with a similar technique. ${ }^{8}$ Moreover, the absence of detectable contractions in the distal oesophagus has not been reported in healthy subjects. ${ }^{8}$ Acute gut distension inhibits the motility of the other tracts of the intestine by reflex relaxation. ${ }^{10}$ However, this mechanism can hardly be the cause of the severe impairment of oesophageal motility found in our five patients as colonic distension was chronic and as in the remaining nine patients oesophageal motility was entirely normal despite colonic dilatation.

Simultaneous contractions occur in patients with diffuse oesophageal spasm and in achalasia. ${ }^{11}$ However, even if the normal resting pressure of the LOS in our patients and the normal relaxation observed in two of them does not exclude a chance association with these diseases, ${ }^{11-13}$ they make it more unlikely. Simultaneous oesophageal contractions and megacolon were described in patients with Chagas' disease. ${ }^{14}$ A negative complement fixation test for Trypanosoma cruzi might have been helpful to exclude this disease. In such patients however the resting pressure of the LOS is often raised; moreover in Europe Trypanosoma cruzi is not endemic and Chagas' disease has been reported only in immunosuppressed subjects. ${ }^{15}$

The absence of detectable contractions in the distal oesophagus recalls the pattern of motility observed in patients with visceral myopathy and megaduodenum ${ }^{1-3}$ or with end stage systemic sclerosis. ${ }^{16}$ None of our patients, however, had a dilated duodenum or a family history of the disease that characterises patients with visceral myopathy and megaduodenum, ${ }^{1-3}$ nor did any of them have Raynaud's phenomenon or cutaneous changes, which characterise patients with systemic sclerosis. ${ }^{16}$

The absence of anorectal inhibitory reflex in three patients may indicate Hirschsprung's disease ${ }^{17}$ One of our patients had spontaneous daily evacuations, however, which is very uncommon in adult patients with Hirschsprung's 
disease. ${ }^{17}$ A higher frequency of oesophageal simultaneous contractions was observed in children with this disease, ${ }^{18}$ suggesting a more widespread neuropathy. Our results show that in presence of a Hirschsprung's disease-like impairment of anorectal inhibitory reflex, extracolonic impairment of gut motility is also possible.

Three of our five patients with impaired oesophageal motility had constipation and pseudo-obstruction. Both Watier et $a l^{19}$ and Reynolds et $a l^{20}$ pointed out that oesophageal manometry may be a simple test to detect a generalised motor disorder in subjects with constipation. The latter authors found abnormal oesophageal motility in six of 25 patients $(25 \%)$ with severe constipation, one of them with diffusely dilated small and large bowel. ${ }^{20}$ Moreover, oesophageal motility is often impaired in patients with pseudo-obstruction, ${ }^{2}$ a clinical picture that may have many causes. ${ }^{21}$ Interestingly our study showed that the presence of megacolon represents in itself a hallmark of a motor disorder not limited to the colon independently of associated symptoms.

All our patients with oesophageal motor impairment had localised megacolon sparing the rectum and a varying part of the sigmoid. It has been speculated that localised megacolon could be explained by hindgut dysgenesis or by ischaemia in the vascular territory of the inferior mesenteric artery. ${ }^{22}$ Our results suggest a more widespread visceral neuropathy or myopathy, the oesophageal pattern of low amplitude multiple peaked simultaneous contractions suggesting the first of these and the absence of detectable contractions the second.

The finding of an oesophageal motor impairment in patients with megacolon may have practical implications for their treatment and follow up. A variety of surgical options are available to treat megacolon and megarectum including colectomy with ileorectal anastomosis ${ }^{23}$ and anal or low rectal anastomosis with pouch construction. ${ }^{24}$ The coexistence of a generalised motor disorder in these patients seem to discourage such approaches. ${ }^{23} 24$ The natural history of the subset of patients with megacolon and impaired oesophageal motility is still unknown, however, and the role of surgery in their treatment remains unclear.

We are grateful to Association Amici della Gastroenterologia del Padiglione Granelli for financial support, $\mathbf{R}$ Fasoli, $M$ Paravicini, and T Ranzi for referral of patients and Alix Green for reviewing the English text.
1 Faulk DL, Anuras S, Gardner D, Mitros FA, Summers RW, Christensen J. A familial visceral myopathy. Ann Intern Med 1978; 89: 600-6.

2 Schuffler MD, Rohrmann CA, Chaffee RG, Brand DL Delaney $\mathrm{JH}$, Young $\mathrm{JH}$. Chronic intestinal pseudoobstruction. A report of 27 cases and review of the literature. Medicine 1981; 60: 173-96.

3 Rodrigues CA, Shepherd NA, Lennard-Jones JE, Hawley PR, Thompson HH. Familial visceral myopathy: a family with at least six involved members. Gut 1989; 30: 1285-92.

4 Shaw A, Shaffer H, Teja K, Kelly T, Grogan E, Bruni C. A perspective for pediatric surgeons: chronic idiopathic intestinal pseudoobstruction. F Pediatr Surg 1979; 14 719-27.

5 Eaves ER, Schmidt GT. Chronic idiopathic megaduodenum in a family. Aust $N Z \mathcal{F}$ Med 1985; 15: 1-6.

6 Lennard-Jones JE. Clinical features of idiopathic megarectum and megacolon in adults. In: Kamm MA Lennard-Jones JE, eds Constipation Petersfield: Wrightson Biomedical. 1994: 225-31.

7 Preston DM, Lennard-Jones JE, Thomas B. Towards a radiologic definition of idiopathic megacolon. Gastrointest Radiol 1985; 10: 167-9.

8 Richter JE, Wu WC, Johns DN, Blackwell JN, Nelson JL Castell JA, et al. Oesophageal manometry in 95 healthy adult volunteers. Variability of pressures with age and frequency of "abnormal" contractions. Dig Dis Sci 1987 32: 583-92.

9 Simon R. Confidence intervals for reporting results of clinical trials. Ann Intern Med 1986; 105: 429-35.

10 Basilisco G, Phillips SF. Ileal distention relaxes the canine colon: a model of megacolon? Gastroenterology 1994; 106: 606-14.

11 Vantrappen G, Janssens J, Hellemans J, Coremans G. Achalasia, diffuse esophageal spasm and related motility disorders. Gastroenterology 1979; 76: 450-7.

12 Katz PO, Richter JE, Cowan R, Castell DO. Apparent complete lower esophageal sphincter relaxation in achalasia. Gastroenterology 1986; 90: 978-83.

13 Tokumine F, Muto Y, Okushima N, Kusano T, Nakaci A Yamazato $\mathrm{M}$, et al. A rare case of achalasia coexistent with sigmoid megacolon and associated with epilepsy. Gastroenterol 1994; 29: 637-41.

14 Ferreira-Santos R. Megacolon and megarectum in Chagas' disease. Proc $R$ Soc Med 1961; 54: 1047-53.

15 Villalba R, Fornes G, Alvarez MA, Roman J, Rubio V, Fernandez $\mathbf{M}$, et al. Acute Chagas' disease in a recipient of a bone marrow transplant in Spain: case report. Clin Infect Dis 1992; 14: 594-5.

16 Stevens MB, Hookman P, Siegel CI, Esterly JR, Shulman LE, Hendrix TR. Aperistalsis of the esophagus in patients with connective-tissue disorders and Raynaud's phenomenon. N Engl f Med 1964; 270: 1218-22.

17 Barnes PRH, Lennnard-Jones JE, Hawley PR, Todd IP. Hirschsprung's disease and idiopathic megacolon in adults and adolescents. Gut 1986; 27: 534-41

18 Staiano A, Corazziari E, Andreotti MR, Clouse RE Esophageal motility in children with Hirschsprung's disease. American fournal of Diseases of Children 1991; 145: 310-3.

19 Waitier A, Devroede G, Duranceau A, Abdel-Rahman M, Duguay $\mathrm{C}$, Forand $M$, et al. Constipation with colonic inertia. A manifestation of systemic disease. Dig Dis $S c i$ 1983; 28: 1025-33.

20 Reynolds JC, Ouyang A, Lee CA, Baker L, Sunshine AG, Cohen S. Chronic severe constipation. Prospective motility studies in 25 consecutive patients. Gastroenterology 1987; 92: 414-20.

21 Christensen J, Orvar K. Chronic pseudo-obstruction. In Kumar D, Wingate D, eds. An illustrated guide to gastrointestinal motility. 2nd ed. Edinburgh; Churchill Livingstone. 1993: 567-82.

22 Likongo Y, Devroede G, Shang JC, Arhan P, Vobecky S, Navert $\mathrm{H}$, et al. Hindgut dysgenesis as a cause of constipation with delayed colonic transit. Dig Dis Sci 1985; 31: 993-1003.

23 Stabile G, Kamm MA, Hawley PR, Lennard-Jones JE. Colectomy for idiopathic megarectum and megacolon Gut 1991; 32: 1538-40.

24 Stewart J, Kumar D, Keighley MRB. Results of anal or low rectal anastomosis and pouch construction for megarectum and megacolon. Br f Surg 1994; 81: 1051-3. 